\title{
Co-Payment(Co-Financing) Patiens Diagnosed with Arterial Hipertension and Dislipidemia
}

\author{
Doina Margaritti \\ geconta@yahoo.ro \\ Ovidius University of Constanta, Romania
}

\begin{abstract}
High blood pressure is the highest risk factor attributed to mortality. Conformable the forecasts of specialized bodies one-third of adults around the world will be affected by hypertension by 2025. Despite public health programs and effective pharmacotherapy for hypertension in developed economies, about $25 \%$ of adults have hypertension. This condition remains untreated in proportion up to $50 \%$, and blood pressure is only controlled in a proportion of $50 \%$. This financial contribution of patients affects significantly its own budget is also a cause of the increase in the number of those who do not condition.
\end{abstract}

Key words: economic efficiency, antihipertensive, community pharmacy, national programs, co-financing.

JEL Code: I11, L65, P52

\section{Introduction}

Hypotension is one of the most common chronic non-transmissible diseases. Blood pressure increases with age and is believed to reflect environmental factors and lifestyle. Increased arterial stiffness results in TAS augmentation and TAD diminution and is also responsible for increasing the prevalence of isolated systolic hypertension in the elderly. In addition, hypertension has a higher prevalence among women and ethnic minorities in predominantly Western countries. [2]

\section{Primary hypertension}

Specialists appreciate that hypertension comes from the interaction of multiple genetic traits that are individually responsible for small increases in blood pressure, but can be responsible for 30$50 \%$ of individual variation, environmental factors and lifestyle that raise blood pressure are responsible for the rest.

High blood pressure pharmaceutical products include non-steroidal anti-inflammatory drugs, corticosteroids, calcineurin inhibitors, oral hormonal contraceptives and female hormonal substitutes, stimulant sympathomimetic drugs and illegal drugs, sweet wood, salt (sodium chloride), and alcohol. Other factors contributing to increased blood pressure are: a sedentary lifestyle and a low-fat diet in fruit and vegetable consumption, as well as high fat diets and carbohydrates that lead to obesity.

In cases where there is no identifiable cause for hypertension, the term primary hypertension is preferred to essential hypertension. [3]

\section{Secondary arterial hypertension}

According to statistics, 5-10\% of hypertensive patients, an identifiable, possibly reversible or treatable cause of hypertension can be elucidated by careful assessment of the causes that are largely classified: in the case of renal, vascular, endocrine and neuronal diseases.

In patients under the age of 30, patients with sudden onset, severe hypertension, and patients with hypertension, the most common secondary causes found in resistant hypertension are obstructive sleep apnea or bilateral adrenal hyperplasia which causes excess mineralocorticoid.[3] 
Hypertension is treated to reduce the risk of major cardiovascular and renal events. Therefore, isolated treatment versus other modified cardiovascular risk factors (hyperlipidemia, diabetes mellitus, smoking, obesity) is inadequate.

\section{Dyslipidemia}

Dyslipidemia is an important factor of modifiable risk for cardiovascular disease caused by high cholesterol levels.

To reduce cholesterol and other dyslipidemia levels it is recommended to reduce LDL-C (low density lipoprotein) levels as the main goal of lipid therapy and lower overall high cholesterol high-density lipoprotein cholesterol levels as a secondary endpoint.

Changes in lifestyle, such as diet and exercise, can improve dyslipidemia. In the treatment of dyslipidemia, statins are recommended for the first line, and other classes include fibrates, niacin, bile acid sequestrants and cholesterol absorption inhibitors.

In the treatment of dyslipidemia, statins are recommended for the first line, and other classes include fibrates, niacin, bile acid sequestrants and cholesterol absorption inhibitors.

\section{The objective of the study}

The objective of this study is to evaluate the costs of original medicines that are more costly than generic medicines, due to preclinical clinical and preclinical studies before launching into the pharmaceutical market.

A comparison was also made between the costs of treatment of hypertension and dyslipidaemia based on a prescription-compensated original drug and the cost of generic treatment for a period of 30 days. At the same time, the objective of the study is to establish the financial contribution of patients (co-payment), which affects the family budget, a contribution established in both treatments with original medicines and generic medicines.

\section{Materials and methods}

The materials used to carry out the study are those provided by the community pharmacy studied but also the recipe of an older patient diagnosed with arterial hypertension and dyslipidemia Thus, we evaluated pharmaco-economically the compensated recipe of a 78-year-old pensioner with a pension of less than 990 lei, diagnosed with primary hypertension and hypercholesterolemia.

The patient under study is on the following medications:

Zofenopril $7.5 \mathrm{mg}-1$ tablet / day (Morning)

Bisoprolol $5 \mathrm{mg}$ - 1 tablet / day (Morning)

Clopidogrel $75 \mathrm{mg}-1$ tablet / day (Lunch)

Atorvastatin $10 \mathrm{mg}-1$ tablet / day (Evening)

\section{List of Levels of Medication Compensation:}

List A: List of drugs with a level of compensation of $90 \%$ of the reference price.

List B: List of drugs with a level of compensation of $50 \%$ of the reference price.

List C1: List of drugs with a 100\% compensation level of the reference price

\section{Results and discussions}

Pharmacoeconomics can be considered a branch of the health economy that deals with identifying, measuring and comparing the costs and consequences of pharmaceutical products and services. It helps build an economic relationship that combines drug research, production and distribution, storage, prices and subsequent use by humans. Some of the concepts involved in the pharmaco-economic analysis include cost reduction, cost-effectiveness, cost benefits, and cost utility analysis. Pharmacoeconomics can be of great help in decision-making when assessing accessibility and access to the right medicine to the right patient at the right time when comparing two drugs in the same class of medicines. This helps determine that the 
manufacturer's claims for a medicinal product are justified. Proper application of the pharmacy economy will allow practitioners and pharmacists to make better and more informed decisions about the products and services they offer. [5]

Farmacoeconomics is a sub-discipline of the health economics interested in the evaluation of pharmaceutical products and services in terms of costs. Research identifies, measures and compares costs and results of pharmaceutical products and services with healthcare systems and society. In the last decades, the importance of pharmaco-economics has increased due to the new direction of considering the cost of drug therapy along with its safety and efficacy. This is a challenge for health care providers to offer the optimal choice of pharmaceuticals and services at an appropriate price. The overall aim of the pharmaco-economics is to provide an acceptable balance between the economic, humanistic and clinical outcomes of therapy. In addition, pharmaco-economics plays a crucial role in clinical decisions, formulation management, pharmaceutical reimbursement, price negotiations, drug management and user guides of medicines. [6]

Following the study, we presented in table no. 2, the retail price for the original and generic prescription drugs to treat the condition in the case study, respectively the cost of the full price treatment for both variants.

Table no. 2 The Retail Price of Original Medicines vs. generic prescriptions for the treatment of hypertension associated with dyslipidemia / hypercholesterolemia (RON)

\begin{tabular}{|c|c|c|c|c|c|c|}
\hline $\begin{array}{l}\text { Nr. } \\
\text { crt }\end{array}$ & $\begin{array}{c}\text { Active } \\
\text { substance }\end{array}$ & List & $\begin{array}{l}\text { Original } \\
\text { medicine }\end{array}$ & $\begin{array}{l}\text { Retail } \\
\text { price }\end{array}$ & $\begin{array}{l}\text { Generic } \\
\text { medicine }\end{array}$ & $\begin{array}{l}\text { Retail } \\
\text { price }\end{array}$ \\
\hline 1. & $\begin{array}{l}\text { Zofenopril } \\
7,5 \mathrm{mg}\end{array}$ & B & $\begin{array}{c}\text { Zomen } 7,5 \mathrm{mg} \\
\text { x } 28 \mathrm{cp} .\end{array}$ & 20,43 & $\begin{array}{lr}\text { Zomen } & 7,5 \mathrm{mg} \times 28 \\
\mathrm{cp} .(\mathrm{nu} & \text { exista } \\
\text { varianta } & \text { generica }\end{array}$ & 20.43 \\
\hline 2. & $\begin{array}{l}\text { Bisoprolol } \\
5 \mathrm{mg}\end{array}$ & A & $\begin{array}{c}\text { Concor } 5 \mathrm{mg} \mathrm{x} \\
30 \mathrm{cp} .\end{array}$ & 15,45 & $\begin{array}{c}\text { Bisoblock } 5 \text { mg x } 30 \\
\text { cp }\end{array}$ & 3,67 \\
\hline 3. & $\begin{array}{l}\text { Clopidogrel } \\
75 \mathrm{mg}\end{array}$ & C1 & $\begin{array}{c}\text { Plavix } 75 \mathrm{mg} \mathrm{x} \\
28 \mathrm{cp} .\end{array}$ & 46,14 & $\begin{array}{c}\text { Trombex } 75 \text { mg x } 30 \\
\text { cp. }\end{array}$ & 17,43 \\
\hline 4. & $\begin{array}{l}\text { Atorvastatin } \\
10 \mathrm{mg}\end{array}$ & B & $\begin{array}{l}\text { Sortis } 10 \mathrm{mg} \mathrm{x} \\
\quad 30 \mathrm{cp} .\end{array}$ & 26,9 & Atoris $10 \mathrm{mg} \mathrm{x} 30 \mathrm{cp}$. & 10,97 \\
\hline- & - & - & $\begin{array}{c}\text { Treatment } \\
\text { value } \\
\text { without } \\
\text { compensation }\end{array}$ & 108.51 & $\begin{array}{c}\text { Treatment value } \\
\text { without } \\
\text { compensation }\end{array}$ & 52.50 \\
\hline
\end{tabular}

Source: Own processing

As seen in the table above, the cost of treatment in the original version is 108.51 ron, compared to the cost of treatment in the generic version, which is 52.50 ron, with the mention that for the active substance Zofenopril there is no generic variant, taking taking into account the original Zomen $7.5 \mathrm{mg}$ x $28 \mathrm{cp}$ (retail price is 20.43 ron).

Choosing the original or generic treatment variant is a patient's benefit, both of which have the same effect, the difference being the amount to be borne from the patient's own pocket.

Table no.3 shows the value of the total price that the patient will pay (co-payment) for a 30-day treatment with the original medicines, generic medicines, for the category of retired insured with incomes less than 990 ron. 
Table no. 3. Comparative Sitting on Co-Payment in Original Version vs. alternative generic (ron)

\begin{tabular}{|c|c|c|c|c|}
\hline \multirow{2}{*}{$\begin{array}{l}\mathrm{Nr} . \\
\mathrm{crt}\end{array}$} & \multicolumn{2}{|c|}{ Co-payment amount ron } & \multicolumn{2}{|c|}{ Co-payment amount ron } \\
\hline & Original medicine & $\begin{array}{c}\text { Co } \\
\text { - payment }\end{array}$ & Generic medicine & $\begin{array}{c}\text { Co } \\
\text { - payment }\end{array}$ \\
\hline 1. & Zomen 7,5 mg x $28 \mathrm{cp}$. & $\begin{array}{l}\text { 18,56/cutie } \\
19,88 / 30 \mathrm{cp} .\end{array}$ & - & 19,88 \\
\hline 2. & Concor 5 mg x $30 \mathrm{cp}$ & 11,04 & $\begin{array}{c}\text { Bisoblock } 5 \text { mg x } 30 \\
\text { cp }\end{array}$ & 0,37 \\
\hline 3. & Plavix $75 \mathrm{mg} \mathrm{x} 28 \mathrm{cp}$. & $\begin{array}{l}\text { 31,96/cutie } \\
34,24 / 30 \text { cp. }\end{array}$ & $\begin{array}{c}\text { Trombex } 75 \mathrm{mg} \mathrm{x} \\
30 \mathrm{cp} .\end{array}$ & 1,74 \\
\hline 4. & Sortis $10 \mathrm{mg} \mathrm{x} 30 \mathrm{cp}$. & 16,48 & $\begin{array}{c}\text { Atoris } 10 \text { mg x } 30 \\
\text { cp. }\end{array}$ & 1,10 \\
\hline & Original medicine & $\begin{array}{c}\text { Total cost }(30 \\
\text { days of treatment) } \\
=81.64 \text { ron }\end{array}$ & Generic medicine & $\begin{array}{l}\text { Total cost } \\
\text { (30 days of } \\
\text { treatment) } \\
=23,09 \text { ron }\end{array}$ \\
\hline
\end{tabular}

Source: Own processing

As can be seen from the table above, the patient will pay as a co-payment in the generic treatment variant a difference of 58.55 lei less than in the original treatment.

This phenomenon can be appreciated both from the point of view of affecting the patient's own budget, but also from the point of view of the State that reduces the cost of medication in the prescription and choice of treatment options with generic drugs.

\section{Conclusions of the study}

The study shows that there is a difference in significant value in the treatment with original medicines and in the treatment of generic medicines, obvious choice of the right medicine will also have to take into account the bioequivalence studies, the pharmaceutical form, the genetic predisposition of the patient.

The pharmaco-economic study may play an important role in establishing and selecting treatment for hypertensive disorders and dyslipidaemia.

Hospitals should also recruit healthcare professionals with pharmaco-economic expertise to manage and manage resources regardless of their nature and, in particular, financial resources allocated to health services regardless of healthcare or medical treatment so limited in the budget national health.

In order to achieve the best results, it is necessary to initiate studies of data collection and statistical, epidemiological, demographic data, plus data on clinical practice models, resource use, costs and health assessments.

Partnerships should also be developed to develop relevant regional databases and registers.

When developing a pharmaco-economic evaluation, it is recommended to collaborate with a researcher who has experience in conducting such studies. It is also necessary to invest in pharmacy education and training in pharmacolog.

\section{References}

1. S.R. Group, J.T. Wright Jr., J.D. Williamson, et al., Arandomized trial of intensive versus standard bloodpressure control, N Engl J Med, 373 (2015), p: 2103-2106;

2. National Institute for Health and Care Excellence, Hypertension: clinical management of primary bypertension in adults. Clinical Guideline no. 127, National Clinical Guideline Centre, London (2011);

3. Shradha Bhagani, Vikas Kapil, Melvin D.Lobo, Hypertension, Pathogenesis, risk factors and prevention, Medicine, Volume 46, Issue 9, September 2018, p: 509-515; 
International Conference "Risk in Contemporary Economy" ISSN-L 2067-0532 ISSN online 2344-5386

$X^{\text {th }}$ Edition, 2019, Galati, Romania,

"Dunarea de Jos" University of Galati, Romania - Faculty of Economics and Business Administration

4. Carrie Palmer, New Directions in Managing Dyslipidemia, The Journal for Nurse Practitioners, Available online 28 November 2018;

5. Mahendra Rai, Richa Goyal, Chapter 33 - Pharmacoeconomics in Healthcare, Pharmaceutical Medicine and Translational, Clinical Research 2018, Pages 465-472;

6. Qais Alefan PhD, Shaymaa AlImam M Pharm, Tareq Mukattash PhD, Nizar Mhaidat

7. PhD, Ibrahim Alabbadi PhD, Karen Rascati PhD, Pharmacoeconomics education in WHO Eastern Mediterranean region, Currents in Pharmacy Teaching and Learning, Volume 7, Issue 6, NovemberDecember 2015, p: 819-825. 